\title{
Pengembangan Potensi Wisata di desa Wisata Yehembang Kangin Kecamatan Mendoyo Kabupaten Jembrana
}

I Gusti Made Dwi Candra Anggara a,1 Ida Ayu Suryasih a,2

1dwicandra073@gmail.com 2idaayusuryasih@unud.ac.id

a Program Studi Sarjana Destinasi Pariwisata, Fakultas Pariwisata, Universitas Udayana, Jl. Dr. R. Goris, Denpasar, Bali 80232 Indonesia

\section{ABSTRACT}

Village of Yehembang Kangin is one of tourism village which has various tourism potential inside which have not been optimized as a tourism destination or tourist attraction. The purpose of this studies to know potential of tourism in the Yehembang Kangin Village Tourism and know the efforts to development of tourism potential in the Yehembang Kangin Tourism Village.

The research method used in this research, is a qualitative research, where the qualitative research used, observation, in-depth interview technique and qualitative documents. The concept of tourism supporting components in formulating the existing conditions in the Yehembang Kangin Tourism Village. And data analysis technique used in this research is descriptive qualitative.

The results of this research is Yehembang Kangin Village have two potensial tourism among others is natural and culture potential tourism and the effort to the development of tourism potential in the Tourism Village Yehembang Kangin there are two aspects is mapping of tourist attractions and local community empowerment in the Village Tourism Yehembang Kangin.

Key Words Potential Tourism, Tourist Attractions, Yehembang Kangin Village Tourism

\section{PENDAHULUAN}

Sektor pariwisata dalam bidang perekonomian merupakan sektor penggerak masyarakat yang diharapkan dapat menjadi berkelanjutan melalui pengembangan pariwisata berbasis masyarakat. Menurut Hadiwijoyo (2012) dalam menciptakan pembangunan pariwisata berbasis berkelanjutan, memerlukan suatu stretegy dalam menciptakan daya tarik wisata dengan memiliki wisata berbasis masyarakat dalam meningkatkan kesejahteraan dari masyarakat lokal, pelestarian budaya, dan sistem kepariwisataan ramah lingkungan. Seperti halnya pada aktivitas pariwisata yang memulai dan menciptakan pembangunan pariwisata berkelanjutan dengan membentuk desa wisata dengan memiliki ciri kawasan wisata perdesaan yang dapat dijadikan daya tarik wisata.

Desa Yehembang Kangin merupakan satu diantara bebrapa desa wisata di Kabupaten Jembrana yang mempunyai beragam suatu potensi wisata yang tentunya sangat menarik untuk dikembangkan sebagai atraksi wisata, baik dari potensi alam maupun potensi budayanya. Desa Wisata Yehembang Kangin memiliki keunikan maupun suatu ciri khas yang menjadi daya tarik tersendiri bagi wisatawan untuk memutuskan berkunjung ke Desa Wisata Yehembang Kangin yaitu diantaranya dari potensi seni budaya jegog khas Jembrana dalam pementasan seni di Desa Yehembang Kangin dan kesakralan Pura Dang Kahyangan Rambut Siwi yang menjadi daya tarik sendiri bagi wisatawan dan sebagai stopover bagi wisatawan yang melakukan perjalanan jauh. Selain itu Desa Wisata Yehembang Kangin memiliki potensi alam pantai, sungai dan Hutan yang menjadi satu wilayah di Desa Wisata. Salah satu contohnya yang sedang berkembang adalah Desa Wisata Yehembang Kangin menyuguhkan keindahan alam sungai dan perbukitan dengan view menarik, serta tersedianya fasilitas penunjang dengan atraksi wisata yang ditawarkan oleh pihak Pokdarwis Desa Wisata Yehembang Kangin selaku pengelola diantaranya wisata trekking dan river tubing. Masyarakat lokal Desa Yehembang Kangin ikut terlibat dalam pengembangan suatu Desa Wisata dan membentuk suatu kelompok masyarakat yang sudah di tetapkan oleh Pemerintah Kabupaten Jembrana dengan Surat Keputusan Dinas Pariwisata dan Kebudayaan Kabupaten Jembrana Nomor 19/PR/DISPARBUD/2017 tentang pengukuhan kelompok sadar wisata di Kabupaten Jembrana.

Pengembangan pada Desa Wisata Yehembang Kangin saat ini memiliki beberapa kendala yang menghambat perkembangan desa wisata ini. Kendala yang dihadapi Desa Wisata Yehembang Kangin ini yaitu kurang optimalnya pengembangan Desa Wisata dalam 
memanfaatkan berbagai potensi yang ada di Desa Yehembang Kangin dan minimnya informasi terkait daya tarik wisata yang terdapat di Desa Wisata Yehembang Kangin. Desa Wisata Yehembang Kangin memiliki beragam suatu atraksi wisata, tetapi pada kenyataan saat ini desa wisata Yehembang Kangin belum banyak diketahui wisatawan secara luas. Adapun kendala yang signifikan dalam upaya pengembangan potensi wisata yang ada di Desa Wisata Yehembang Kangin adalah respon masyarakat yang pesimis menangapi pengaruh dan pembangunan pariwisata di desanya. Sehingga dengan fenomena tersebut penting dan menarik dilakukan penelitian untuk mengangkat topik dan mencari suatu solusi. Sehingga, pengelolaan Desa Wisata dalam memanfaatkan berbagai potensi yang ada di Desa Yehembang Kangin sangat dibutuhkan untuk pengembangan desa wisata yang lebih optimal dari sebelumnya.

\section{KEPUSTAKAAN}

\subsection{Telaah Penelitian sebelumnya}

Penelitian ini mengambil dan membandingkan dari beberapa jurnal terkait dengan penelitian ini. Adapun acuan penelitian yang pertama adalah penelitian yang dilakukan oleh Sagita (2018) mengenai strategi pengembangan potensi di Desa Pangsan sebagai Desa Wisata Petang Kabupaten Badung. Acuan penelitian kedua yaitu memiliki kesamaan focus penelitian yaitu mengenai potensi Desa Pinge Sebagai Desa Wisata di Marga, Tabanan yang diteliti oleh Suryawan (2014) dan yang terkahir acuan penelitian ketiga yang memiliki kesamaan lokasi di Desa wisata jembrana mengenai Motivasi Wisatawan dalam mengunjungi Desa Wisata Blimbingsari, Jembrana yang diteliti oleh Utama (2017).

\subsection{Landasan Konsep}

Penelitian ini menggunakan lima konsep untuk menganalisis dan menelaah suatu permasalahan dalam tulisan ini yaitu konsep Desa wisata (Suwatoro,1997), konsep komponen pengembangan Desa Wisata (Karyono, 1997), konsep potensi wisata (Pendit ,1999), konsep pemberdayaan masyarakat (Mardikanto dan Soebiato dalam pratiwi 2015) dan konsep Pemetaan (Abidin, 2007).

\section{METODE PENELITIAN}

Penelitian ini berlokasi di di Desa Wisata Yehembang Kangin. Desa Wisata Yehembang Kangin adalah sebuah desa administratif yang terletak di Desa Yehembang Kangin, Mendoyo, Kabupaten Jembrana, Provinsi Bali. Lokasi detailnya terletak kurang lebih $96 \mathrm{~km}$ sebelah barat Pusat Kota Denpasar. Desa ini memiliki luas wilayah 20.737.963,9 Ha/m2 yang terdiri dari lima banjar adat antara lain; Banjar Tibusambi, Tegak Gede, Nusamara, Bangli dan Banjar Sumbul.

Teknik pengumpulan data dalam penelitian ini menggunakan teknik pengumplan data observasi. Observasi dilakukan di lokasi penelitian yaitu Desa Wista yehembang Kangin untuk mengamati gambaran yang jelas mengenai potensi wisata di Desa Wisata Yehembang Kangin. Kemudian melakukan wawancara mendalam dengan informan yakni Perbekel Desa Yehembang Kangin, Ketua Pokdarwis dan anggota Pokdarwis, mengenai upaya pengembangan potensi wisata di Desa Wisata Yehembang Kangin. Selain teknik observasi dan wawancara, dalam penelitian ini juga menggunakan teknik studi kepustakaan dengan penelusuran dokumen penelitian sebelumnya yang memiliki kesamaan pada focus penelitian.

Adapun sumber data yang dipakai dalam penelitian ini dibagi menjadi dua yaitu; sumber data primer dan data sekunder. Data primer dalam penelitian ini adalah data mengenai gambaran umum Desa Wisata Yehembang Kangin, potensi wisata desa wisata Yehembang Kangin, pemetaan atraksi serta pemberdayaan masyarakat lokal. Data Sekunder dalam penelitian ini berupa profil Desa Yehembang Kangin yang berupa letak geografis, dan dokumentasi kegiatan wisata di Desa Yehembang Kangin.

Teknik analisis data dalam penelitian ini menggunakan teknik analisis deskriptif kualitatif. Teknik analisis ini memiliki tiga langkah yaitu pertama reduksi data, adapaun yang dimaksud data ini adalah mengenai data gambaran umum Desa Wisata Yehembang kangin, wawancara mengenai kondisi eksisting Desa Wisata berserta potensi Desa, selanjutnya langkah kedua yaitu penyajian data yang 
dilakukan dengan menyajikan data yang telah direduksi seperti hasil wawancara dalam bentuk naratif dan gambaran mengenai kondisi potensi Desa Wisata Yehembang Kangin, dan yang terakhir adalah kesimpulan, dalam penelitian ini adalah data yang diperoleh dan akan diverifikasi sesuai topik sehingga dapat menghasilkan data actual mengenai pengembangan potensi wisata di Desa Wisata Yehembang Kangin.

\section{IV.HASIL DAN PEMBAHASAN}

\subsection{Potensi Wisata Desa Yehembang}

Hasil dari penelitian ini menunjukkan bahwa Desa Wisata Yehembang Kangin memiliki potensi wisata yang dapat dibagi menjadi dua, yaitu potensi alam dan buatan.

\subsubsection{Potensi Alam Desa Wisata Yehembang Kangin}

Potensi alam yang dimiliki oleh Desa Wisata Yehembang Kangin yakni diantaranya potensi alam perbukitan, hutan dan perairan sungai. Untuk potensi alam perbukitan di Desa Wisata Yehembang Kangin saat ini, sudah terdapat daya tarik wisata alam yang terletak di Banjar Tegak Gede yaitu wisata desa love garden. Dengan memanfaatkan pemandangan dari atas perbukitan di Banjar Tegak Gede yang memiliki view alam perdesaan dan perairan sungai dibawahnya, menjadikan wisata desa love garden memiliki beberapa atraksi wisata seperti flying fox, rumah pohon dan beberapa spot foto selfi menarik seperti gembok cinta, ayunan cinta dan anjungan diatas perbukitan. Adapun spot foto selfi ini merupakan atraksi wisata yang banyak diminati oleh anak - anak hingga remaja pada khususnya.

Selain potensi perbukitan, Desa Yehembang Kangin memiliki potensi sungai dan hutan yang berada di wilayah Desa Yehembang Kangin yakni khususnya di Banjar Nusamara dan Banjar Bangli Adapun beberapa potensi sungai dan hutan di Desa Yehembang Kangin yang sudah menjadi atraksi wisata yaitu diantaranya atraksi wisata Wisata Motor trail, atraksi wisata Green Clif, Camping Ground dan river tubing di Banjar Nusamara dengan melintasi sungai di Kawasan Desa Yehembang Kangin, selain itu masuk ke Kawasan hutan terdapat jalur tracking yang dibuat oleh kelompok sadar wisata yang dimana wisata trekking ini merupakan satu satunya jalur menuju ke daya tarik wisata air terjun Nusamara yang terletak disekitar $\pm 3 \mathrm{~km}$ dari atraksi wisata river tubing.

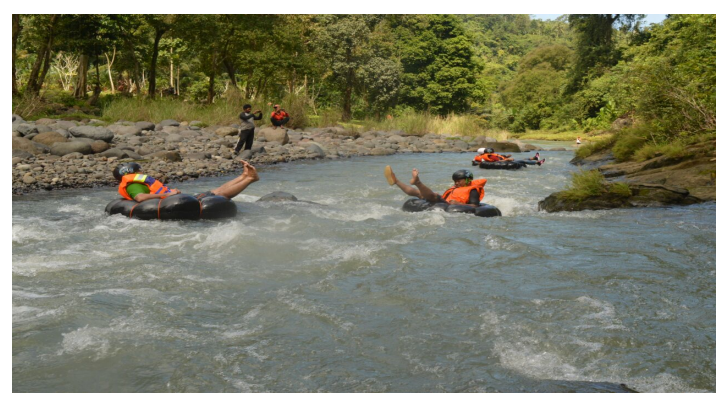

Gambar 1. Atraksi Wisata River Tubing di Banjar Nusamara

Sumber: Dokumentasi Pokdarwis, 2018

\subsubsection{Potensi Budaya Desa Wisata Yehembang Kangin}

Potensi budaya yang dimiliki Desa Yehembang Kangin diantaranya DTW Pura Rambut Siwi dan tradisi kesenian jegog, yang dimana salah satu Potensi wisata budaya yaitu Pura Rambut Siwi ini sudah ditetapkan sebagai daya tarik wisata di Kabupaten Jembrana dengan Surat Keputusan Bupati nomor 16 tahun 2001. Kawasan daya tarik wisata ini ini sudah didukung dengan sarana wisata seperti tersedianya areal parkir, toilet, wantilan dan bangunan wantilan budaya sebagai tempat pertemuan serta loket tiket masuk wisatawan. Untuk memasuki kawasan suci pura ini, wisatawan terlebih dahulu membayar tiket masuk sebesar 5.000rupiah dan menyewa sarung (kamen) seharga Rp 10.000 (obito,2018). Di sepanjang jalan raya sebelah utara kawasan pura dan parkir pura terdapat beberapa warung makan atau restaurant dan tempat istirahat (rest area) bagi wisatawan yang melakukan perjalanan jauh. Dengan keunikan dan kemegahan Pura Dang Khayangan Rambut Siwi ini, sering dikunjungi wisatawan baik mancanegara maupun nusantara terutama pada hari libur dengan melakukan aktivitas berfoto dikawasan pura yang diijinkan ataupun ingin mengetahui sejarah dan budaya di Pura Rambut Siwi.

Potensi Budaya lainnya yang bersifat potensi budaya fisik yaitu tradisi seni jegog yang dimana seni jegog adalah alat musik ciri khas kabupaten Jembrana, yang dimiliki Desa Wisata Yehembang Kangin dalam 
mengadakan suatu pementasan jegog antar banjar yang bertempat di Balai Desa Yehembang Kangin banjar tegak gede yang menjadi daya tarik wisata tersendiri bagi wisatawan dalam mengunjungi Desa Wisata Yehembang Kangin.

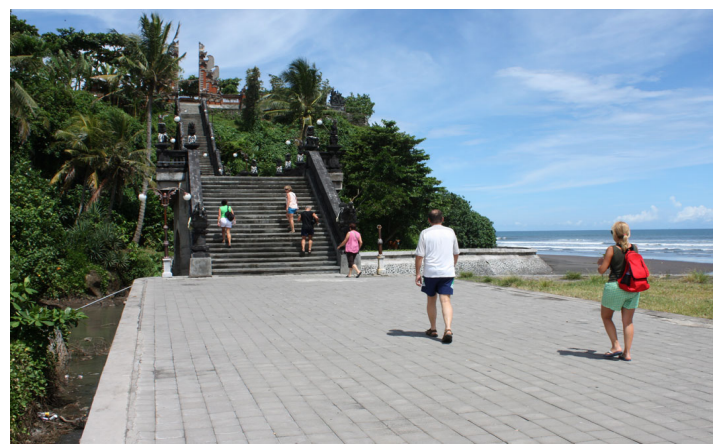

Gambar 2. Wisatawan berkunjung ke Pura Rambut Siwi

Sumber: google image, 2018

\subsection{Pengembangan Potensi Wisata Desa Wisata Yehembang Kangin}

\subsubsection{Pemetaan Atraksi Wisata}

Desa Wisata Yehembang Kangin memiliki beragam potensi dan atraksi yang ada, namun tidak semua potensi dan atraksi wisata yang ada di Desa Wisata ini sudah dapat dikatakan berjalan secara optimal. Sehingga sangat diperlukan upaya dalam mengatasi permasalahan tersebut.

Permasalahan yang sangat mendasar Desa Wisata ini dikatakan belum bisa mengoptimalkan potensinya yaitu kurangnya informasi mengenai atraksi wisata yang ada di Desa Wisata Yehembang Kangin. Sehingga untuk mengatasi hal ini diperlukan suatu identifikasi dan pemetaan suatu atraksi wisata di Desa Yehembang Kangin. Desa Wisata Yehembang Kangin terdiri lima dusun atau banjar yang dimana tiga banjar di Desa Wisata ini sudah memiliki atraksi wisata utama yang sudah dikembangkan dan berpotensi mendatangkan banyak wisatawan yaitu diantaranya Banjar Nusamara, Banjar Bangli dan Banjar Tegak Gede. Adapun identifikasi atraksi wisata dapat dijabarkan pada tabel berikut ini:
Tabel 4.1

Identifikasi Atraksi Wisata di Desa Wisata Yehembang

\begin{tabular}{|c|c|c|c|}
\hline No & $\begin{array}{l}\text { Nama } \\
\text { Daya } \\
\text { Tarik }\end{array}$ & $\begin{array}{c}\text { Jenis } \\
\text { Atraksi }\end{array}$ & Lokasi \\
\hline 1 & $\begin{array}{l}\text { River } \\
\text { Tubing }\end{array}$ & \multirow{5}{*}{$\begin{array}{l}\text { Wisata } \\
\text { Alam }\end{array}$} & \multirow[b]{3}{*}{ Br. Nusamara } \\
\hline 2 & $\begin{array}{l}\text { Camping } \\
\text { Ground }\end{array}$ & & \\
\hline 3 & $\begin{array}{c}\text { Wisata } \\
\text { Tracking } \\
\text { dan Air } \\
\text { terjun } \\
\text { Nusamara }\end{array}$ & & \\
\hline 4 & $\begin{array}{c}\text { Wisata } \\
\text { Green Clift }\end{array}$ & & \multirow[b]{2}{*}{ Br. Bangli } \\
\hline 5 & $\begin{array}{c}\text { Wisata } \\
\text { Motor } \\
\text { Trail }\end{array}$ & & \\
\hline 6 & $\begin{array}{l}\text { Wisata } \\
\text { Love } \\
\text { Garden }\end{array}$ & $\begin{array}{l}\text { Wisata } \\
\text { Buatan }\end{array}$ & \multirow{3}{*}{$\begin{array}{l}\text { Br. Tegak } \\
\text { Gede }\end{array}$} \\
\hline 7 & $\begin{array}{c}\text { Pura } \\
\text { Rambut } \\
\text { Siwi }\end{array}$ & \multirow{2}{*}{$\begin{array}{l}\text { Wisata } \\
\text { Budaya }\end{array}$} & \\
\hline 8 & $\begin{array}{l}\text { Kesenian } \\
\text { Jegog }\end{array}$ & & \\
\hline
\end{tabular}

Sumber: Hasil Penelitian,2018

Keberadaan setiap daya tarik wisata di Desa Wisata Yehembang Kangin ini sebenarnya memiliki potensi dan atraksi wisata yang tidak sama. Karena berbagai potensi pada daya tarik wisata ini dapat menjadi faktor pendorong dalam upaya pemetaan atraksi wisata. Potensi dan atraksi wisata yang ada di Desa Wisata Yehembang Kangin, dapat berupa atraksi wisata alam, buatan dan budaya yang tercantum pada tabel 4.1. Dengan pemetaan atraksi wisata ini diharapkan akan dapat membantu menangani masalah kepariwisataan yang terdapat di Desa Wisata Yehembang Kangin. Melalui identifikasi dari sebaran potensi wisata yang terdapat di Desa Wisata Yehembang Kangin, agar dapat membantu pihak pengelola Desa Wisata dalam mengemas suatu produk wisata. 


\subsubsection{PemberdayaanKelompok Masyarakat}

Desa Wisata Yehembang Kangin membentuk suatu kelompok masyarakat yaitu kelompok sadar wisata yang diberi nama POKDARWIS Buana Kanti. Kelompok sadar wisata ini memiliki baberapa kendala dan masih harus berbenah dalam mengembangkan Desa Wisata Yehembang Kangin seperti contoh belum bisa mengkemas produk wisata, pengetahuan yang kurang terkait kegiatan kepariwisataan, media pemasaran pariwisata yang masih kurang, belum mampu menjadi pemandu lokal (guide local) dan penguasaan bahasa asing yang masih rendah. Dalam menyikapi hal ini pemberdayaan masyarakat sangat diperlukan guna pengembangan potensi suatu Desa Wisata dapat dikatakan berjalan secara optimal. Adapun proses pemberdayaan masyarakat yang dapat dilakukan dalam mengembangkan suatu Desa Wisata yaitu diantaranya.

1. Melakukan kegiatan sosialisasi dan penyuluhan' mengenai konsep desa wisata kepada Pokdarwis Desa Wisata Yehembang Kangin.

Tahap penyuluhan dan sosialisasi mengenai konsep desa wisata ini akan dipaparkan oleh pembicara yang mengetahui tentang desa wisata tersebut kepada Pokdarwis Desa Yehembang Kangin mengenai konsep desa wisata agar nantinya kelompok sadar wisata ini paham tentang konsep desa wisata yang meliputi ciri cirinya, karakteristik desa, sapta pesona, dan upaya dalam mengembangkan potensi wisata.

2. Pelatihan kepemanduan (guide training)

Pelaksanaan program ini secara menyeluruh melibatkan partisipasi dari Pokdarwis Desa Wisata Yehembang Kangin dan masyarakat lokal sekitar dengan tujuan untuk meningkatkan pengetahuan dan skill dalam prosedur kepemanduan (guide training) di Desa Wisata Yehembang Kangin. Seperti contoh dalam pelatihan kemampuan Bahasa asing guna menghadapi wisatawan yang datang ke Desa wisata Yehembang Kangin.

3. Pelatihan keselamatan dan kesehatan kerja Pelaksanaan pelatihan keselamatan dan kesehatan kerja ini melibatkan pengelola Desa Wisata Yehembang Kangin (Pokdarwis), dan masyarakat lokal desa yehembang wisata kangin yang terlibat dalam kegiatan pariwisata. Tujuan pelatihan ini untuk memenuhi SOP pekerjaan sebagai pengelola suatu daya tarik wsata. Pelatihan keselamatan dan kesehatan kerja ini memiliki output yaitu masyarakat paham dan sadar akan bahaya dan resiko aktivitas wisata yang bisa terjadi. Seperti diambil contoh pada atraksi wisata river tubing di Desa Wisata Yehembang Kangin terdapat pelatihan mengenai keselamatan dan kenyamanan sepanjang pengarungan sungai oleh pemandu lokal yang tentunya sudah berkompeten dan mengetahui sistem operasional pada kegiatan wisata river tubing sebelum disosialisasikan kepada wisatawan.

4. Pelatihan menyusun produk wisata yang akan digunakan dalam membuat kemasan paket wisata.

Dalam pelatihan menyusun produk wisata, masyarakat lokal akan diajarkan menyusun suatu paket wisata berdasarkan potensi yang ada. Hal ini dilakukan untuk mempermudah menyasar suatu target pasar wisatawan, serta dengan dibuatnya pemetaan atraksi wisata akan memudahkan dalam mengelompokan atraksi pada paket wisata yang bisa dibuat, dalam pembuatan paket wisata akan dipandu oleh pemandu yang tentunya sudah mengetahui sistem pengemasan suatu paket wisata. Dalam pengemasan ini juga akan dipasarkan melalui biro perjalanan seperti travel wisata maupun wisatawan yang berkunjung' ke Desa Wisata Yehembang Kangin untuk mencoba paket wisata yang disusun.

5. Pelatihan menyusun biaya dan harga dari kemasan paket wisata perdesaan.

Dalam penyusunan biaya dan harga kemasan paket wisata perdesaan ini tentunya harus memerlukan ketelitian di dalam menghitung tarif untuk satu paket wisata yang akan dikoordinasikan kepada biro perjalanan wisata yang akan diajak bekerjasama di dalam menjalankan serta memasarkan paket wisata perdesaan ini. 
Sehingga masyarakat lokal akan dilatih di dalam penyusunan rancangan biaya yang akan ditetapkan bersama.

6. Mengemas dan mencetak paket wisata dalam bentuk media cetak maupun media sosial.

Pelatihan ini mengkhusus pada mendesain serta mencetak paket - paket wisata perdesaan yang ada di Desa Wisata Yehembang Kangin. Tentunya di dalam pembuatan desainannya tersebut harus dikemas lebih menarik agar nantinya wisatawan akan lebih banyak tertarik untuk membelinya serta wisatawan merasa puas di dalam menikmatinya. Selain dalam bentuk brosur dan pembuatan pada media cetak, paket wisata dibuat dalam sebuah buku panduan wisata. Selain media cetak tentunya design paket wisata dikemas melalui media sosial seperti Instagram, facebook, website, blog untuk menarik minat kunjungan wisatawan tidak hanya domestik tetapi wisatawan mancanegara.

7. Mengadakan kerjasama dan perjanjian dengan Biro Perjalanan wisata.

Pembuatan paket wisata tentunya tidak dapat berjalan sendiri tanpa adanya saluran distribusi yang mempromosikan serta memasarkannya. Jadi di dalam memasarkan paket wisata yang dibuat tentunya akan dibantu oleh travel agent yang membantu dalam pemasaran paket wisata perdesaan yang sudah disusun. Namun, sebelum itu tentunya akan ada suatu (Mou) atau nota kesepahaman antara kedua belah pihak dalam mengadakan kerjasama pemasaran paket wisata.

8. Melakukan pengawasan dan evaluasi

Ketika paket wisata yang sudah terbentuk dan laku di kalangan pangsa pasar yang dituju, perlu adanya kegiatan monitoring yang dilakukan secara rutin serta adanya evaluasi di akhir. Evaluasi yang dibahas yaitu kelancaran dari penjualan paket wisata perdesaan tersebut dan kendala yang dialami selama memasarkan suatu paket wisata, serta yang terakhir yaitu melakukan pembukuan seperti paket wisata yang sudah mendapatkan penjualan perharinya atau perbulan.

\section{PENUTUP}

\subsection{Kesimpulan.}

Dari hasil penelitian yang tlah dilakukan terdapat dua simpulan umum yang dapat disampaikan sebagai hasil dari penelitian ini. Simpulan-Simpulan yang disampaikan tersebut diantaranya adalah:

1. Potensi Wisata di Desa Wisata Yehembang Kangin

Desa Yehembang Kangin memiliki potensi wisata yang dapat dibagi menjadi dua, yaitu diantaranya potensi alam dan budaya. Adapun beberapa potensi alam yang ada di Desa Wisata Yehembang Kangin yakni diantaranya potensi alam perbukitan, potensi hutan dan perairan sungai. Selain itu Desa Wisata Yehembang Kangin juga memiliki dua potensi wisata budaya yang salah satunya sudah menjadi daya tarik wisata yng sudah ditetapkan yaitu wisata budaya Pura Rambut Siwi dan tradisi budaya kesenian jegog.

2. Pengembangan Potensi Wisata Di Desa Wisata Yehembang

Desa Wisata Yehembang Kangin dalam pengembanga potensi wisatanya diperlukan suatu pemetaan atraksi wisata agar dapat membantu menangani masalah kepariwisataan yang terdapat di Desa Wisata Yehembang Kangin yaitu melalui identifikasi dari sebaran potensi wisata yang terdapat di Desa Yehembang Kangin. Selain itu dalam pengembangannya Desa Wisata Yehembang Kangin membentuk suatu kelompok masyarakat yang tergabung dalam kelompok sadar wisata Buana Kanti. Dalam menjalankan aktivitas pariwisata di Desa Wisata Yehembang Kangin, pokdarwis ini memiliki beberapa kendala dalam mengelola Desa Wisata Yehembang Kangin. Sehingga perlu proses pemberdayaan masyarakat yang dapat dilakukan dalam mengembangkan suatu Desa Wisata. 


\subsection{Saran}

Adapun terdapat tiga saran yang ditujukan kepada masyarakat lokal, Pemerintah dan wisatawan dalam penelitian ini yakni sebagai berikut:

1. Kepada Masyarakat Lokal

Masyarakat lokal yang tidak tergabung dalam lembaga penunjang pariwisata di Desa Wisata Yehembang Kangin sebaiknya ikut serta berpartisiapsi dan mendukung segala aktivitas kepariwisataan yang dilaksanakan oleh lembaga penunjang pariwisata baik pemerintah, desa adat, kelompok tani ikan ataupun pokdarwis guna mengoptimalkan pengembangan pariwisata di Desa wisata Yehembang Kangin agar lebih baik lagi.

2. Kepada Pemerintah

Pemerintah selaku pemegang kebijakan di kelembagaan kepariwisataan seharusnya melakukan evaluasi dan monitoring secara optimal dan bertahap agar dapat mengetahui setiap perubahan dalam fenomena pariwisata yang ada seperti kekurangan dan kerusakan fasilitas di beberapa atraksi wisata. Selain itu pemerintah diharapkan cepat tanggap dalam menanggapi permasalahan yang ada di beberapa aspek kepariwisataan dari segi atraksi, aksesbilitas, fasilitas pendukung serta kelembagaan pengelola wisata yaitu pokdarwis yang masih perlu sosialisasi mengenai konsep desa wisata dan mendapatkan beberapa pelatihan guna penguatan sumber daya manusia dalam menunjang aktivitas pariwisata di Desa Wisata Yehembang Kangin.

3. Kepada Wisatawan

Kepada wisatawan yang datang ke Desa Wisata Yehembang Kangin diharapkan selalu mematuhi peraturan desa (pararem Desa Yehembang Kangin) yang telah dibuat oleh pihak pengelola desa wisata serta prajuru adat dan selalu menjaga kebersihan sehingga tercipta lingkungan desa wisata yang bersih.

\section{DAFTAR PUSTAKA}

Anonim. Republik Indonesia. 2010. Undang-Undang tentang Kepariwisataan.

Abidin, H. Z. 2007. Konsep Dasar Pemetaan. Bandung: ITB. Kelompok Keilmuan Geodesi.
Hadiwijoyo, S.S. 2012. Perencanaan Pariwisata Perdesaan Berbasis Masyarakat, Yogyakarta; Graha Ilmu,

Karyono, Hari, 1997. Kepariwisataan. Jakarta: Gramedia Widia Sarana.

Pendit, Nyoman. 1999.Ilmu Pariwisata. Jakarta: Akademi Pariwisata Trisakti.

Pratiwi, K. R. I., Pascarani, N. N. D., \& Winaya, I. K. (2016). Evaluasi Pelaksanaan Program One Village One Product dalam Pemberdayaan Masyrakat di Desa Pelaga, Kecamatan Petang, Kabupaten Badung.

Sagita, Putu Agus Wikanatha. 2018. Strategi Pengembangan Desa Pangsan sebagai Desa Wisata di Kecamatan Petang Kabupaten Badung.

Suryawan, Ida bagus dkk. 2014. Potensi Desa Pinge Sebagai Desa Wisata di Kecamatan Marga, Kabupaten Tabanan.Jurnal Desatinasi Pariwisata

Suwantoro. 1997. Dasar - Dasar Pariwisata. Yogyakarta: Penerbit Andi. Systematc Linkange. Gramedia: Jakarta.

Utama, I Gusti Bagus Rai. 2017. Motivasi wisatawan mengunjungi Desa Wisata Blimbingsari, Jembrana. Jurnal Kajian Bali. 